\title{
The double burden of malnutrition and cardiometabolic risk widens the gender and socio-economic health gap: a study among adults in Burkina Faso (West Africa)
}

\author{
Augustin N Zeba ${ }^{1,2}$, Hélène F Delisle ${ }^{1, *}$, Genevieve Renier ${ }^{3}$, Boubacar Savadogo ${ }^{2}$ and \\ Banza Baya ${ }^{4}$ \\ 'Département de Nutrition, Faculté de Médecine, Université de Montréal, CP 6128 succ. Centre-ville, Montréal, \\ Quebec, Canada, H3C 3J7: ${ }^{2}$ Institut de Recherche en Sciences de la Santé/Direction Régionale de I'Ouest \\ (IRSS/DRO), Bobo-Dioulasso, Burkina Faso: ${ }^{3}$ Centre Hospitalier Universitaire de Montréal, Département de \\ Médecine, Université de Montréal, Montréal, Quebec, Canada: ${ }^{4}$ Institut Supérieur des Sciences de la Population \\ (ISSP), Université de Ouagadougou, Ouagadougou, Burkina Faso
}

Submitted 21 July 2011: Final revision received 21 December 2011: Accepted 3 February 2012: First published online 30 March 2012

\begin{abstract}
Objective: To document the double burden of malnutrition and cardiometabolic risk factors (CMRF) in adults and its occurrence according to different sociodemographic parameters.

Design: Population-based cross-sectional observational study. We first randomly selected 330 households stratified by tertile of the income levels proxy as low, middle and high income.

Setting: Northern district of Ouagadougou, the capital city of Burkina Faso.

Subjects: In each income stratum, 110 individuals aged 25-60 years and who had lived permanently in Ouagadougou for at least 6 months were randomly selected, followed with collection of anthropometric, socio-economic and clinical data, and blood samples.

Results: The overall obesity/overweight prevalence was $24 \cdot 2 \%$ and it was twice as high in women as in men $(34.1 \% v .15 \cdot 5 \%, P<0 \cdot 001)$. Hypertension, hyperglycaemia and low HDL cholesterol prevalence was $21.9 \%, 22 \cdot 3 \%$ and $30.0 \%$, respectively, without gender difference. The prevalence of the metabolic syndrome was $10 \cdot 3 \%$. Iron depletion and vitamin A deficiency affected $15 \cdot 7 \%$ and $25.7 \%$ of participants, respectively, with higher rates in women. Coexistence of at least one nutritional deficiency and one CMRF was observed in $23.5 \%$ of participants, and this 'double burden' was significantly higher in women than in men $(30 \cdot 4 \% v \cdot 16 \cdot 1 \%, P=0 \cdot 008)$ and in the low income group.

Conclusions: CMRF are becoming a leading nutritional problem in adults of Ouagadougou, while nutritional deficiencies persist. The double nutritional burden exacerbates health inequities and calls for action addressing both malnutrition and nutrition-related chronic diseases.
\end{abstract}

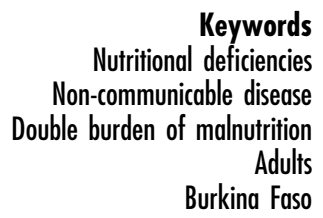

Keywords

Nutritional deficiencies Double burden of malnutrition

Burkina Faso
The nutrition transition with progressive Westernisation of diets and sedentary lifestyles, propelled by socio-economic and technological development as well as globalisation and accelerated urbanisation, has led developing countries, and particularly their urban areas, to experience a rise of non-communicable diseases ${ }^{(1-3)}$. Among these non-communicable diseases, CVD and diabetes as cardiometabolic risk factors (CMRF) ${ }^{(4)}$ and the metabolic syndrome (MetS) have been recognised to be directly related to nutrition ${ }^{(5)}$. CMRF show an escalating trend in most developing countries and are becoming leading contributors to the burden of diseases, death and disability $^{(6,7)}$. A recent meta-analysis reported that over a period of 15 years (1990 to 2005), the trend of obesity prevalence in West Africa increased by $114 \%$, with urban women being 4.79 times more affected than men ${ }^{(8)}$. Although studies on CMRF in Sub-Saharan Africa are scarce, they suggest that CMRF prevalence rates are similar to those reported in Western countries, with for instance hypertension reaching $29 \cdot 4 \%$ and $40 \cdot 2 \%$ in urban adults in Ghana and Burkina Faso, respectively $^{(9,10)}$, and diabetes reaching $6 \cdot 8 \%$ in Nigeria and $6 \cdot 3 \%$ in Ghana ${ }^{(11)}$.

Meanwhile, global and micronutrient malnutrition remains highly prevalent, even in adults. Indeed, studies in Sub-Saharan Africa have reported that more than $20 \%$ 
of women have $\mathrm{BMI}<18 \cdot 5 \mathrm{~kg} / \mathrm{m}^{2}, 57 \cdot 1 \%$ are anaemic and $18.5 \%$ are deficient in vitamin $\mathrm{A}^{(12,13)}$.

Research usually focuses on either malnutrition or CMRF, seldom on both. Evidence suggests that the nutrition transition in developing countries is occurring rapidly, which contributes to the double burden of malnutrition, i.e. the overlap of CMRF and malnutrition within the same population group, the same household or the same individual ${ }^{(14-17)}$. Few studies have addressed the issue of this double nutritional burden, and they have primarily considered the overlap of overweight/obesity and undernutrition in populations as a whole ${ }^{(18,19)}$ or within households ${ }^{(15,16)}$. The double burden of malnutrition and CMRF in individuals has been little studied $^{(20,21)}$, particularly in Sub-Saharan Africa where it is poorly documented ${ }^{(22)}$.

Since WHO recognised non-communicable diseases as an epidemic in the developing world, public health concern has increased. However, the need to halt the epidemic should not be at the expense of nutritional deficiency disorders. The challenge of these programmes is especially complex in settings where epidemiological data related to population-attributable risk for various factors are not readily or reliably available at present. Relevant research in a country-specific manner should be implemented to comprehend the dimensions, as well as the dynamics, of the double burden of malnutrition. A cross-sectional study carried out in Ouagadougou, Burkina Faso was designed to assess cardiometabolic risk and nutritional deficiency markers in adults. One of the hypotheses was that the double burden of malnutrition is frequent, particularly among women. The present paper reports on the double burden phenotypes and occurrence according to sociodemographic parameters.

\section{Methods}

\section{Population and sample}

The study was carried out in 2010 in the northern part of Ouagadougou where a population observatory has been in operation since 2008, with periodic collection of socio-economic, sociodemographic and health data in a population sample of 80000 people. This part of the capital city is a vulnerable area according to data from national and international institutions ${ }^{(23)}$. The study sample of 330 adults aged 25-60 years and stratified by income was selected using the observatory database. The availability of data on this part of Ouagadougou such as the household identification, socio-economic and demographic data argued for our study location. The database included 13021 households with at least one individual between 25 and 60 years of age. A proxy of household income was derived using principal component analysis, with twelve discriminatory household asset variables (ownership of house, telephone, television, DVD, fridge, motorbike, car, type of household toilet, electricity, type of cooking fuel, and type of floor, roof and walls). Households were split into three tertiles of this income proxy. For each tertile, 110 households were randomly selected, with fifty additional individuals as alternatives. Only one individual per household was enrolled. The field team consisted of a medical doctor (the first author) and an experienced laboratory technician and two research assistants trained by the first author.

Eligible participants were born-Burkinabè adults aged 25 to 60 years who had been living in Ouagadougou for at least 6 months and would remain there until the end of the study. Persons with prior hypertension or diabetes were retained in the study. Pregnant or lactating women, as well physically and mentally disabled persons, were excluded.

A sample size of 300 adults aged 25 to 60 years was adequate on the basis of an estimated prevalence of $10 \%$ of concurrent overweight/obesity and micronutrient deficiency within the same individual, taking into account the overweight/obesity prevalence of $33 \%{ }^{(10)}$ and the limited access to micronutrient-rich foods in $65.6 \%$ of households in Ouagadougou ${ }^{(24)}$. The precision was $\pm 3 \%$, and the confidence interval was $95 \%$ with $\alpha<0.05$ using the software PASS (Power Analysis and Sample Size) supplied by NCSS (Kaysville, UT, USA). The size of the sample was increased by $10 \%$ up to 330 , to provide for drop-outs, missing participants and incomplete data sets.

\section{Variables}

After enrolment, personal interviews were performed with participants to collect data on age, parity, education level, psychosocial factors and lifestyle patterns. Anthropometric and clinical data as well as blood samples were also collected. Psychosocial and lifestyle data are not presented here.

\section{Anthropometrics}

Body weight was measured to the nearest $100 \mathrm{~g}$, with participants in light clothing and without shoes, using a portable electronic scale of $150 \mathrm{~kg}$ capacity (Seca 803 Clara Scale, Semur-en-Auxois, France). Height was measured to the nearest $0.5 \mathrm{~cm}$ using a portable locally built stadiometer, with the participants standing upright on a flat surface without shoes and with the back of their heels and the occiput against the stadiometer. Waist circumference (WC) was measured to the nearest $0 \cdot 1 \mathrm{~cm}$ with a flexible, non-stretchable and tension-regulated steel tape (Gulick measuring tape ${ }^{\mathbb{C}}$; Creative Health Products, Inc., Plymouth, MI, USA), at the midpoint between the lowest rib and the iliac crest, while participants were standing and breathing normally ${ }^{(25)}$. The averages of two separate measures of body weight, height and WC were used in the analyses. BMI was calculated as weight (in kilograms) divided by the square of height (in metres). BMI was categorised as follows ${ }^{(26)}$ : underweight, BMI $<18.5 \mathrm{~kg} / \mathrm{m}^{2}$; normal weight, $\mathrm{BMI}=18 \cdot 5-24 \cdot 9 \mathrm{~kg} / \mathrm{m}^{2} ;$ overweight, $\mathrm{BMI}=25 \cdot 0-29 \cdot 9 \mathrm{~kg} / \mathrm{m}^{2}$; 
obese, $\mathrm{BMI} \geq 30 \cdot 0 \mathrm{~kg} / \mathrm{m}^{2}$. Abdominal obesity was defined as WC $\geq 102 \mathrm{~cm}$ for men and WC $\geq 88 \mathrm{~cm}$ for women ${ }^{(27)}$.

\section{Blood pressure}

Blood pressure was measured by the first author with a calibrated aneroid sphygmomanometer on the right arm of seated participants after a minimum of 10 min rest. Systolic and diastolic pressures were measured twice with an interval of $10 \mathrm{~min}$ between the first and the second measurement. The mean of the two readings was used in the analyses. Hypertension for individuals without a prior diagnosis was defined as systolic blood pressure (SBP) $\geq 140 \mathrm{mmHg}$ and/or diastolic blood pressure (DBP) $\geq 90 \mathrm{mmHg}^{(28)}$.

\section{Blood sampling and laboratory measures}

Venous blood samples were drawn, after an overnight fast of at least $12 \mathrm{~h}$, into $10 \mathrm{ml}$ EDTA tubes and $10 \mathrm{ml}$ dry tubes for plasma and serum collection, respectively. Blood samples were immediately stored in cold boxes and brought to the laboratory within $2 \mathrm{~h}$. Samples were centrifuged at $3000 \mathrm{rpm}$ for $10 \mathrm{~min}$, aliquoted into cryotubes and frozen at $-32^{\circ} \mathrm{C}$. Fasting glucose was immediately determined on plasma samples using the glucose oxidase method at the University of Ouagadougou. Hyperglycaemia was defined as fasting plasma glucose $>6.1 \mathrm{mmol} / \mathrm{l}$ for individuals without a prior diagnosis ${ }^{(29)}$. Plasma concentrations of HDL cholesterol (HDL-C), LDL cholesterol (LDL-C) and TAG were determined with enzymatic methods. Cut-offs for low HDL-C were $<0.9 \mathrm{mmol} / 1$ for men and $<1.0 \mathrm{mmol} / 1$ for women. The cut-off for high plasma LDL-C was $>3.37 \mathrm{mmol} / \mathrm{l}$. Hypertriacylglycerolaemia was defined as plasma TAG concentration $>1.7 \mathrm{mmol} / \mathrm{l}^{(27)}$. The ratio of total cholesterol (TC) to HDL-C (TC:HDL-C) was calculated and a value $>5$ was defined as high TC:HDL-C ${ }^{(30)}$. Serum insulin concentration was measured by RIA (Cisbio Bioassays, Bagnols sur Ceze, France) and the homeostasis model assessment (HOMA) equation ((fasting glycaemia $\times$ serum insulin)/22.5) was used as an index of insulin resistance; insulin resistance was defined as HOMA-IR $\geq$ last quartile in the whole studied population ${ }^{(31)}$. Serum retinol was measured using HPLC at the University of Ouagadougou, with serum retinol level $<0.7 \mathrm{mmol} / \mathrm{l}$ being indicative of vitamin A deficiency ${ }^{(32)}$. Plasma ferritin level was measured using chemiluminescence with a cut-off of $<15 \mu \mathrm{g} / \mathrm{l}$ for iron depletion, and $\mathrm{Hb}$ was directly measured in the field with a drop of whole blood using a HemoCue ${ }^{\circledR}$ (Hemocue HB $201+$, Angelholm, Sweden) with anaemia being defined as $\mathrm{Hb}<12 \mathrm{~g} / \mathrm{dl}$ in men and $<13 \mathrm{~g} / \mathrm{dl}$ in women ${ }^{(33)}$. Insulin, ferritin and blood lipid determinations were carried out at the University of Nancy (France).

\section{Clustering of deficiency indicators and cardiometabolic risk factors}

Nutritional deficiency indicators considered when assessing the double burden of malnutrition were underweight, iron depletion and vitamin A deficiency, for a maximum of three indicators. Individual CMRF were the following, for a maximum count of four: overweight or obesity or abdominal obesity; hypertension; hyperglycaemia or insulin resistance or diagnosed diabetes; and dyslipidaemia (high LDL-C or low HDL-C or hypertriacylglycerolaemia or high TC:HDL-C). We also considered MetS as the clustering within an individual of hyperglycaemia or insulin resistance or diagnosed diabetes with at least two of the following risk factors: overall obesity $\left(\mathrm{BMI} \geq 30 \cdot 0 \mathrm{~kg} / \mathrm{m}^{2}\right)$, hypertriacylglycerolaemia, low HDL-C and high blood pressure or treated hypertension ${ }^{(27)}$. We used the WHO MetS definition since the cut-offs for individual CMRF were those of WHO.

\section{Statistical analysis}

Data were analysed using the IBM SPSS statistical software package version $18 \cdot 0$ (IBM, Armonk, NY, USA). Results are expressed as means and standard deviations for continuous variables, or as percentages with $95 \%$ confidence intervals for categorical variables. The differences between men and women were assessed using independent $t$ tests or $\chi^{2}$ tests as appropriate. Differences between socio-economic levels were computed using the $\chi^{2}$ test. The level of statistical significance was $P<0 \cdot 05$.

\section{Etbical considerations}

The study was approved by the Ethics Committee of the Faculty of Medicine, University of Montreal, and the Ethics Committee for Health Research of Burkina Faso. The study objectives were clearly explained to participants, selected household heads and local authorities. A written informed consent was obtained from each participant prior to enrolment. They were given back their results on blood pressure and glycaemia, and those with abnormal values were referred for diagnosis and treatment.

\section{Results}

A total of 310 adults $(51.9 \%$ women) completed the study, with a response rate of $94 \%$. Mean age of the population under study was 36.4 (SD 9.0) years (Table 1 ), and women were less educated than men $(P=0 \cdot 05)$.

\section{Malnutrition and cardiometabolic risk factors}

The overall prevalence of anaemia, iron depletion and vitamin A deficiency was $25.5 \%, 15.4 \%$ and $12.7 \%$, respectively (Table 1 ). Anaemia was twice as high in women as in men $(P<0 \cdot 001)$. Iron depletion was four times higher in women than men $(P<0 \cdot 001)$. Vitamin A deficiency was also significantly higher in women than men $(P=0.02)$. Underweight $\left(\mathrm{BMI}<18.5 \mathrm{~kg} / \mathrm{m}^{2}\right)$ prevalence was $9 \cdot 7 \%$, with no sex difference. Low-income and non-educated participants exhibited significantly higher prevalence of vitamin A deficiency (Table 2) compared with high-income and more educated participants 
Table 1 Sociodemographic characteristics, nutritional deficiencies and cardiometabolic risk factors by sex ${ }^{\star}$ among adults $(n$ 310) aged 25-60 years, northern district of Ouagadougou, Burkina Faso, 2010

\begin{tabular}{|c|c|c|c|c|c|c|c|}
\hline & \multicolumn{2}{|c|}{ All $(n$ 310) } & \multicolumn{2}{|c|}{ Women ( $n$ 161) } & \multicolumn{2}{|c|}{ Men (n 149) } & \multirow[b]{2}{*}{$P+$} \\
\hline & Mean or $\%$ & SD or $95 \% \mathrm{Cl}$ & Mean or $\%$ & SD or $95 \% \mathrm{Cl}$ & Mean or \% & SD or $95 \% \mathrm{Cl}$ & \\
\hline Age (years) & $36 \cdot 4$ & $9 \cdot 1$ & $35 \cdot 7$ & $8 \cdot 9$ & $37 \cdot 1$ & $9 \cdot 2$ & $0 \cdot 161$ \\
\hline \multicolumn{8}{|l|}{ Formal education } \\
\hline None & $40 \cdot 3$ & $34 \cdot 8,45 \cdot 8$ & $45 \cdot 3$ & $37 \cdot 6,53 \cdot 0$ & $34 \cdot 9$ & $27 \cdot 3,42 \cdot 5$ & 0.061 \\
\hline Elementary school & $19 \cdot 0$ & $14 \cdot 6,23 \cdot 4$ & $19 \cdot 3$ & $13 \cdot 2,25 \cdot 4$ & $18 \cdot 8$ & $12 \cdot 5,25 \cdot 1$ & 0.913 \\
\hline High school \& above & $40 \cdot 6$ & $35 \cdot 1,46 \cdot 1$ & $35 \cdot 4$ & $28 \cdot 0,42 \cdot 8$ & $46 \cdot 3$ & $38 \cdot 3,54 \cdot 3$ & 0.050 \\
\hline Anaemia & $25 \cdot 5$ & $20 \cdot 7,30 \cdot 3$ & $34 \cdot 8$ & $27 \cdot 5,42 \cdot 1$ & $15 \cdot 4$ & $9 \cdot 6,21 \cdot 2$ & $<0.001$ \\
\hline Iron depletion & $15 \cdot 4$ & $11 \cdot 4,19 \cdot 4$ & $23 \cdot 9$ & $17 \cdot 3,30 \cdot 5$ & $6 \cdot 1$ & $2 \cdot 3,9 \cdot 9$ & $<0.001$ \\
\hline Vitamin A deficiency & $12 \cdot 7$ & $9 \cdot 0,16 \cdot 4$ & $17 \cdot 0$ & $11 \cdot 2,22 \cdot 8$ & $8 \cdot 1$ & $3 \cdot 7,12 \cdot 5$ & 0.020 \\
\hline Underweight & $9 \cdot 7$ & $6 \cdot 4,13 \cdot 0$ & $8 \cdot 1$ & $3 \cdot 9,12 \cdot 3$ & $11 \cdot 4$ & $6 \cdot 3,16 \cdot 5$ & 0.320 \\
\hline Overweight & $16 \cdot 8$ & $12 \cdot 7,20 \cdot 9$ & $23 \cdot 0$ & $16 \cdot 5,29 \cdot 5$ & $10 \cdot 1$ & $5 \cdot 3,14 \cdot 9$ & 0.002 \\
\hline Overall obesity & $7 \cdot 4$ & $4 \cdot 5,10 \cdot 3$ & $11 \cdot 2$ & $6 \cdot 3,16 \cdot 1$ & $3 \cdot 4$ & $0 \cdot 5,6 \cdot 3$ & 0.008 \\
\hline Abdominal obesity & $12 \cdot 5$ & $8 \cdot 8,16 \cdot 2$ & $23 \cdot 7$ & $17 \cdot 1,30 \cdot 3$ & 0.7 & $-0 \cdot 6,2 \cdot 0$ & $<0.001$ \\
\hline Hypertension & 21.9 & $17 \cdot 3,26 \cdot 5$ & $22 \cdot 4$ & $16 \cdot 0,28 \cdot 8$ & $21 \cdot 5$ & $14 \cdot 9,28 \cdot 1$ & $0 \cdot 850$ \\
\hline Hyperglycaemia & $22 \cdot 3$ & $17 \cdot 7,26 \cdot 9$ & $20 \cdot 5$ & $14 \cdot 3,26 \cdot 7$ & $24 \cdot 2$ & $17 \cdot 3,31 \cdot 1$ & 0.430 \\
\hline High LDL-C & $8 \cdot 3$ & $3 \cdot 2,13 \cdot 4$ & $7 \cdot 8$ & $2 \cdot 7,12 \cdot 9$ & $15 \cdot 3$ & $8 \cdot 2,22 \cdot 4$ & $0 \cdot 140$ \\
\hline Low HDL-C & $30 \cdot 0$ & $24 \cdot 9,35 \cdot 1$ & $31 \cdot 7$ & $24 \cdot 5,38 \cdot 9$ & $28 \cdot 2$ & $21 \cdot 0,35 \cdot 4$ & 0.50 \\
\hline High TC:HDL-C & $7 \cdot 1$ & $4 \cdot 3,9 \cdot 9$ & $8 \cdot 7$ & $4 \cdot 4,13 \cdot 0$ & $5 \cdot 4$ & $1 \cdot 8,9 \cdot 0$ & $0 \cdot 250$ \\
\hline Hypertriacylglycerolaemia & 1.9 & $0 \cdot 4,3 \cdot 4$ & 1.9 & $-0 \cdot 2,4 \cdot 0$ & $2 \cdot 0$ & $0 \cdot 2,4 \cdot 2$ & $0 \cdot 750$ \\
\hline Insulin resistance (HOMA-IR $\geq 6 \cdot 77$ ) & $25 \cdot 1$ & $20 \cdot 3,29 \cdot 9$ & $26 \cdot 0$ & $19 \cdot 3,32 \cdot 7$ & $24 \cdot 1$ & $17 \cdot 3,30 \cdot 9$ & 0.690 \\
\hline MetS & $10 \cdot 3$ & $6 \cdot 9,13 \cdot 7$ & $12 \cdot 4$ & $7 \cdot 3,17 \cdot 5$ & $8 \cdot 1$ & $3 \cdot 7,12 \cdot 5$ & 0.206 \\
\hline
\end{tabular}

LDL-C, LDL cholesterol; HDL-C, HDL cholesterol; TC:HDL-C, ratio of total cholesterol to HDL-C; HOMA-IR, homeostasis model assessment-insulin resistance index; MetS, metabolic syndrome.

*This includes twenty-one participants with prior hypertension and two participants with prior diabetes.

tSignificance of the difference between women and men as determined by Student's $t$ test or the $\chi^{2}$ test.

$(25 \cdot 7 \%$ v. $4 \cdot 1 \%, P<0 \cdot 001 ; 21 \cdot 1 \%$ v. $5 \cdot 6 \%, P=0 \cdot 001$ respectively).

The prevalence of insulin resistance, hypertension and hyperglycaemia including previously diagnosed cases was $25 \cdot 1 \%, 21 \cdot 9 \%$ and $22 \cdot 3 \%$, respectively, with no statistical differences between women and men. The prevalence of low HDL-C, high LDL-C, hypertriacylglycerolaemia, high TC:HDL-C ratio and MetS was 30.0\%, 8.3\%, 1.9\%, 7·1\%, and $10 \cdot 3 \%$, respectively, with no sex difference (Table 1 ). Hypertension did not vary either with income or education and was above 18\% in all groups. Hyperglycaemia was significantly more prevalent in the groups with low and medium income compared with the high income group $(P<0 \cdot 001)$, and also was significantly higher in lesseducated participants compared with those who attended high school $(P=0 \cdot 001)$. There was no statistical difference in the prevalence of low HDL-C, high LDL-C, high TC:HDL-C ratio, insulin resistance and MetS according to income or education (Table 2).

The prevalence of overweight, overall obesity and abdominal obesity was $16 \cdot 8 \%, 7 \cdot 4 \%$ and $12 \cdot 5 \%$, respectively, and consistently higher in women than men (Table 1). Overweight, overall obesity and abdominal obesity were $24 \cdot 5 \%, 13 \cdot 3 \%$ and $21 \cdot 4 \%$, respectively, for participants in the high income group and significantly higher compared with low and middle income groups $(P=0 \cdot 045,0 \cdot 025$ and $0 \cdot 003$, respectively). Participants with high school education level exhibited more overall obesity than those with no formal education $(11.9 \% \mathrm{v}$. $2 \cdot 8 \%, P=0 \cdot 010$; Table 2 ).

\section{Coexistence of malnutrition and cardiometabolic risk factors}

As shown in Fig. 1, $72.9 \%$ of the participants had at least one CMRF with $36 \cdot 1 \%$ having at least two risk factors. Additionally $27 \cdot 3 \%$ and $5 \cdot 2 \%$ of the participants had one and two nutritional deficiencies, respectively. Overall $23.5 \%$ exhibited a double burden of malnutrition, with significantly more women than men $(30 \cdot 4 \%$ v. $16 \cdot 1 \%$, $P=0 \cdot 008$; Fig. 2).

Table 3 portrays the five most common phenotypes of the double burden of malnutrition, with $9 \cdot 0 \%$ showing one or two micronutrient deficiencies and at least one CMRF other than overweight/obesity (Phenotype 1 ); $5 \cdot 2 \%$ with one or two micronutrient deficiencies combined with overweight/ obesity and at least one other CMRF (Phenotype 2); 5·2\% with underweight and at least one CMRF (Phenotype 3); $2 \cdot 6 \%$ with one or two micronutrient deficiencies plus MetS (Phenotype 4); and finally $1.6 \%$ with underweight plus one micronutrient deficiency and at least one CMRF (Phenotype 5). Phenotypes 1 and 2 were significantly higher in women than in men $(P=0.030$ and 0.050 , respectively).

Compared with participants who had high school education level, those without formal education (Fig. 3) showed the highest rate of double burden: $32 \cdot 0$ (95\% CI $23 \cdot 9,40 \cdot 1) \% v \cdot 15 \cdot 1(95 \%$ CI $8 \cdot 9,21 \cdot 3) \%(P=0 \cdot 002)$. Similarly, the occurrence of the double burden according to income (Fig. 4) was significantly higher $(P=0 \cdot 005)$ in the group with low income, $32 \cdot 1(95 \%$ CI $25 \cdot 2,42 \cdot 7) \%$, compared with the high income group, $13 \cdot 3$ (95\% CI 6.6, $20 \cdot 0) \%(P=0 \cdot 005)$. 


\section{Discussion}

To our knowledge, the present study one of the first in adults on concurrent nutritional deficiencies and nutritionrelated CMRF in Sub-Saharan Africa. It shows that the double burden of malnutrition within individual adults is widespread in Ouagadougou, and more in women, as well as in less-educated and poorer individuals. The results highlight the fact that $\mathrm{CMRF}$ are taking the lead as nutrition-related problems in adults, while indicators of underweight and micronutrient deficiencies remain highly prevalent, particularly in women. Women are more vulnerable to nutritional deficiencies because of their high nutritional requirements for pregnancy and lactation, and also because of gender inequalities in poverty ${ }^{(34)}$. Cultural factors may also contribute to the higher prevalence of overweight in women ${ }^{(35)}$. The shift towards CMRF in many developing countries has promoted the misconception that diets are moving away from problems of food shortage towards problems of excess food, with nutritional deficiencies becoming a problem of the past ${ }^{(20)}$. Furthermore, the synergistic interaction of 'undernutrition' and 'overnutrition' is all too often overlooked. Besides, 'overnutrition' may be a misnomer for nutrition-related chronic diseases risk since a sizeable proportion of our participants with normal weight or WC showed one or more CMRF (31\%).

Few African studies have reported this double burden of malnutrition beyond the combination of overweight with underweight in the same population. Fewer studies still focus on the double burden in the same individuals. In a study among women of three developing countries (Mexico, Peru and Egypt), Eckhardt et $a l .{ }^{(20)}$ reported that overweight overlapped with anaemia. Studies carried out in developed countries and Latin American countries have reported that lifestyle changes including increasing intake of energy-dense but micronutrient-poor foods, such as high-sugar beverages and high-fat salty snacks, coupled with low intake of micronutrient-rich foods, are pieces of the puzzle that could contribute to explain such overlap of obesity and micronutrient deficiencies ${ }^{(2,20,36,37)}$. However such evidence is lacking in Sub-Saharan Africa, until eating patterns are better documented.

The high prevalence of hypertension in our study is consistent with previous reports in urban Africa ${ }^{(9,38,39)}$; however it seems lower than that previously reported in Ouagadougou $\left(21 \cdot 9 \% v \cdot 40 \cdot 2 \%^{(10)}\right)$, perhaps because of the younger age range in our study. A major concern is that in developing countries, only half of hypertensive individuals are aware of their condition, and of these, only $50 \%$ are under medical treatment, with only $50 \%$ being improved ${ }^{(40)}$. In our study only $30 \%$ of hypertensive participants were aware of their condition with less than half under medical treatment (data not shown).

The prevalence of hyperglycaemia was also high, compared with recent studies in Benin ${ }^{(41,42)}$, even if we 


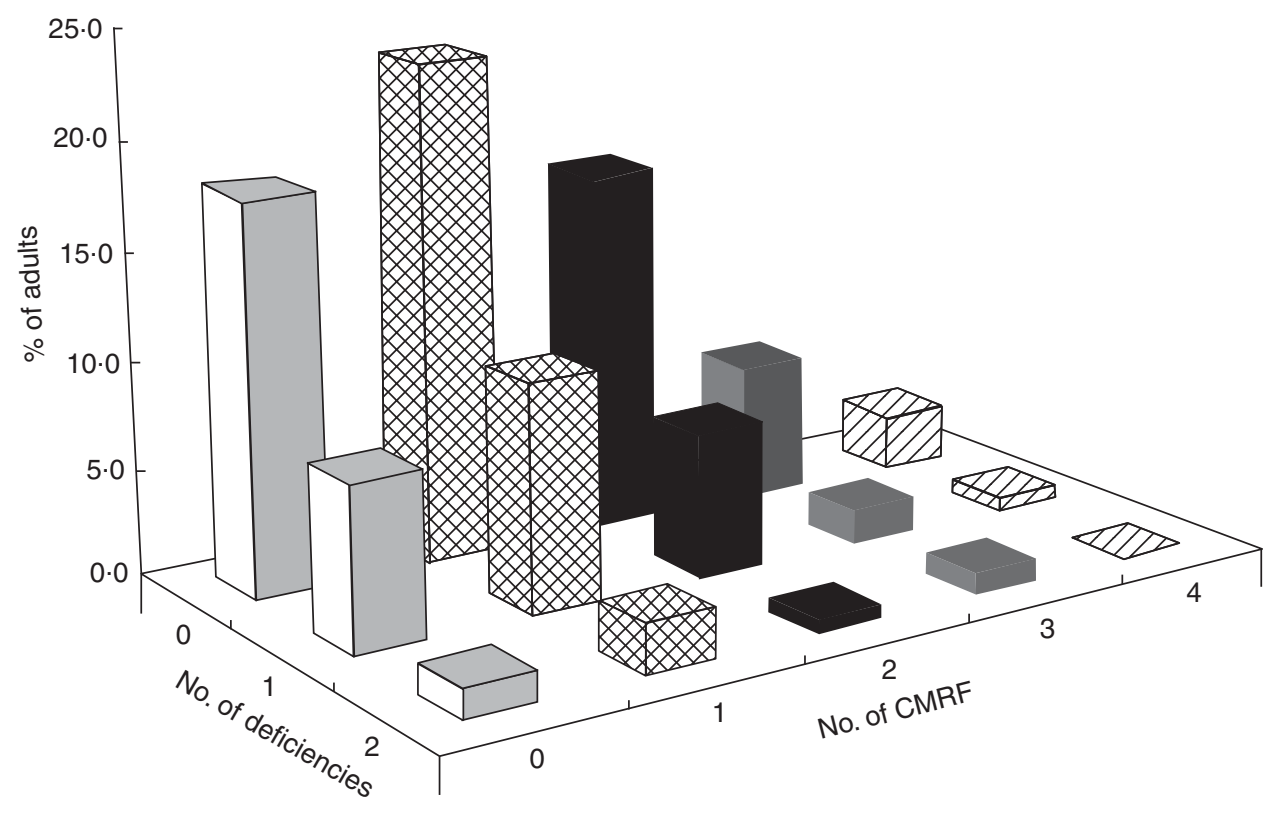

Fig. 1 Clustering of nutritional deficiencies (underweight, iron depletion and vitamin A deficiency) and cardiometabolic risk factors (CMRF) among adults ( $n$ 310) aged 25-60 years, northern district of Ouagadougou, Burkina Faso, 2010

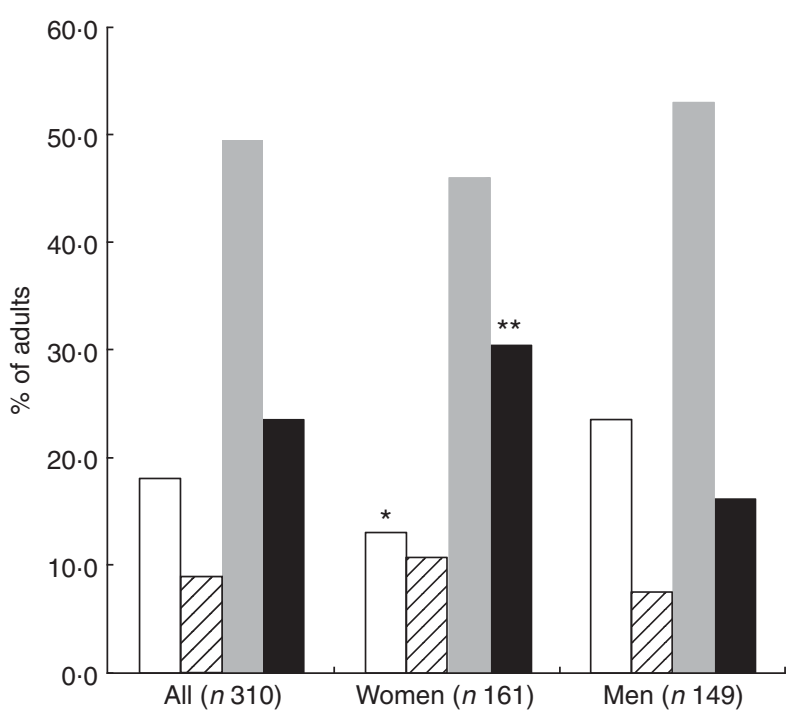

Fig. 2 The occurrence of nutritional deficiencies (underweight, iron depletion and vitamin A deficiency) and cardiometabolic risk factors (CMRF) according to sex among adults ( $n$ 310) aged 25-60 years, northern district of Ouagadougou, Burkina Faso, 2010 ( $\square$, no nutritional deficiencies; $\square$, at least one nutritional deficiency; $\square$, at least one CMRF; $\square$, double burden of nutritional deficiency and (MRF). Mean values were significantly different from those of men (as determined by the $\chi^{2}$ test): ${ }^{\star} P<0.05,{ }^{\star \star} P<0.01$

excluded previously diagnosed cases of diabetes like in the latter studies. The prevalence was significantly higher in the low income group, wherein underweight prevalence was also the highest, suggesting that this metabolic risk factor is no longer a matter of affluence. These results also appear somewhat consistent with the clinical features (i.e. poverty, protein-energy malnutrition, generalised wasting, insulin resistance) of malnutrition-related diabetes or fibrocalculous pancreatic diabetes ${ }^{(43)}$ mostly reported from South Asia ${ }^{(44)}$, but with still limited evidence in Sub-Saharan Africa $^{(45)}$. This should be of particular concern, especially when we are aware that estimates by the International Diabetes Federation suggest the number of adults with diabetes in Sub-Saharan Africa will increase by $98 \%$ from $12 \cdot 1$ million in 2010 to 23.9 million in $2030^{(46)}$.

The low prevalence of hypertriacylglycerolaemia and the rather high prevalence of low HDL-C in our study are noteworthy and consistent with previous studies in Benin (West Africa) $^{(41,42)}$. An extensive review on the African diaspora in the $\mathrm{UK}^{(47)}$ and a recent study including West Africans and African Americans ${ }^{(48)}$ reported a lower propensity of African people to adverse blood lipid profile. However, low HDL-C was rare in the diaspora, which suggests that lifestyle patterns including diet may explain this difference, considering that West Africans are the ancestors of African Americans who have as much as $70 \%$ of their gene pool of West African origin ${ }^{(49)}$. In the present study, the higher prevalence of low HDL-C in the low income group (as shown) and in overweight participants (data not shown) is consistent with an epigenetic or environmental hypothesis, portraying low HDL-C as a particular feature of 'dysnutrition' ${ }^{\text {(50) }}$ (encompassing both 'undernutrition' and 'overnutrition') to be investigated in urban Africans.

The prevalence of overweight, overall obesity and abdominal obesity increased significantly with rising income in our study, suggesting that these populations are at early stages of the nutrition transition, with excess weight 
Table 3 The most common phenotypes of the double burden of malnutrition and CMRF by sex among adults $(n 310)$ aged $25-60$ years, northern district of Ouagadougou, Burkina Faso, 2010

\begin{tabular}{|c|c|c|c|c|c|c|c|}
\hline & \multicolumn{2}{|c|}{ All $(n$ 310) } & \multicolumn{2}{|c|}{ Women ( $n$ 161) } & \multicolumn{2}{|c|}{ Men ( $n$ 149) } & \multirow[b]{2}{*}{$P^{\star}$} \\
\hline & $\%$ & $95 \% \mathrm{Cl}$ & $\%$ & $95 \% \mathrm{Cl}$ & $\%$ & $95 \% \mathrm{Cl}$ & \\
\hline $\begin{array}{l}\text { Phenotype } 1 \text { ( } 1 \text { or } 2 \text { micronutrient deficiencies plus } \geq 1 \text { CMRF } \\
\text { other than overweight/obesity) }\end{array}$ & $9 \cdot 0$ & $5 \cdot 9,12 \cdot 1$ & $12 \cdot 4$ & $7 \cdot 4,17 \cdot 4$ & $5 \cdot 4$ & $1 \cdot 8,11 \cdot 6$ & 0.030 \\
\hline $\begin{array}{l}\text { Phenotype } 2 \text { ( } 1 \text { or } 2 \text { micronutrients deficiencies plus } \\
\text { overweight/obesity and } \geq 1 \text { CMRF) }\end{array}$ & $5 \cdot 2$ & $2 \cdot 8,7 \cdot 6$ & $7 \cdot 5$ & $3 \cdot 5,12 \cdot 5$ & $2 \cdot 7$ & $0 \cdot 1,5 \cdot 3$ & 0.050 \\
\hline Phenotype 3 (Underweight plus $\geq 1$ CMRF) & $5 \cdot 2$ & $2 \cdot 8,7 \cdot 6$ & $4 \cdot 3$ & $1 \cdot 2,7 \cdot 4$ & $6 \cdot 0$ & $2 \cdot 2,9 \cdot 8$ & 0.500 \\
\hline Phenotype 4 ( 1 or 2 micronutrient deficiencies plus MetS) & $2 \cdot 6$ & $0.9,4 \cdot 3$ & $4 \cdot 3$ & $1 \cdot 2,7 \cdot 4$ & $0 \cdot 7$ & $-0 \cdot 6,2 \cdot 0$ & 0.092 \\
\hline $\begin{array}{l}\text { Phenotype } 5 \text { (Underweight plus } 1 \text { micronutrient deficiency } \\
\text { plus } \geq 1 \text { CMRF) }\end{array}$ & $1 \cdot 6$ & $0 \cdot 3,2 \cdot 9$ & $1 \cdot 9$ & $-0 \cdot 2,4 \cdot 0$ & $1 \cdot 3$ & $-0 \cdot 5,3 \cdot 1$ & 0.930 \\
\hline Total double burden of malnutrition & $23 \cdot 5$ & $18 \cdot 8,28 \cdot 2$ & $30 \cdot 4$ & $23 \cdot 3,37 \cdot 5$ & $16 \cdot 1$ & $10 \cdot 2,22 \cdot 0$ & 0.008 \\
\hline
\end{tabular}

CMRF, cardiometabolic risk factors; MetS, metabolic syndrome.

${ }^{*}$ Significance of the difference between women and men as determined by the $\chi^{2}$ test.

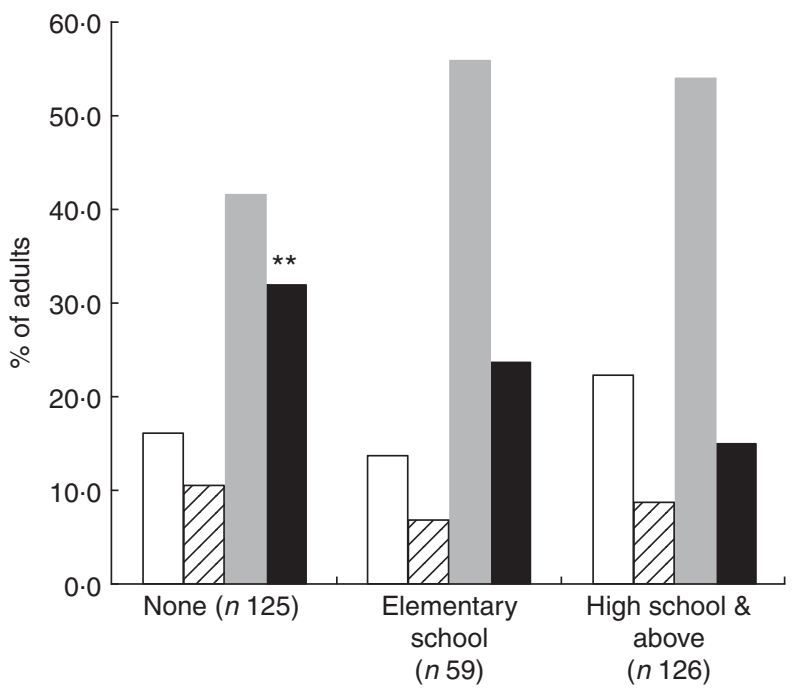

Formal education

Fig. 3 The occurrence of nutritional deficiencies (underweight, iron depletion and vitamin A deficiency) and cardiometabolic risk factors (CMRF) according to formal education among adults ( $n$ 310) aged 25-60 years, northern district of Ouagadougou, Burkina Faso, 2010 ( $\square$, no nutritional deficiencies; $\square$, at least one nutritional deficiency; $\square$, at least one CMRF; $\square$, double burden of nutritional deficiency and CMRF). Mean values were significantly different from those for high school and above (as determined by the $\chi^{2}$ test): ${ }^{\star \star} P<0.01$

primarily among the more affluent, before it progressively shifts to lower-income groups as demonstrated in middleincome countries ${ }^{(51)}$. Women were at least four times more affected by overall obesity than men, which is in line with previous reports in Ouagadougou ${ }^{(52)}$ and other African cities ${ }^{(8,42,53-55)}$. Abdominal obesity, which is known to be more deleterious to health ${ }^{(56)}$ than overall obesity, also prevails in women. Despite this gender difference in overall and abdominal obesity, risk factors like hypertension, hyperglycaemia and dyslipidaemia did not differ between women and men, challenging the relevance of BMI and WC cut-offs for African populations. Several studies in populations of Asian ${ }^{(57)}$ and African ${ }^{(58,59)}$

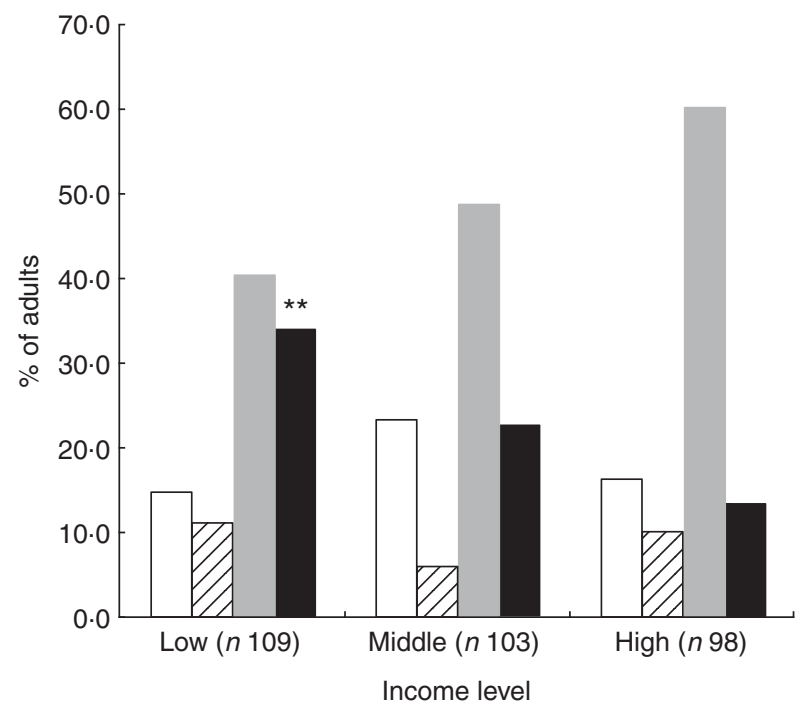

Fig. 4 The occurrence of nutritional deficiencies (underweight, iron depletion and vitamin A deficiency) and cardiometabolic risk factors (CMRF) according to income level among adults ( $n$ 310) aged 25-60 years, northern district of Ouagadougou, Burkina Faso, 2010 ( $\square$, no nutritional deficiencies; $\square$, at least one nutritional deficiency; $\square$, at least one CMRF; $\square$, double burden of nutritional deficiency and CMRF). Mean values were significantly different from those for high income level (as determined by the $\chi^{2}$ test): ${ }^{* \star} P<0.01$

origin have highlighted discrepancies in the relationship between BMI, WC and body fat among different ethnic groups ${ }^{(60-62)}$. This calls for revisiting the obesity cut-off points according to race/ethnic group ${ }^{(63)}$, which would require long-term longitudinal studies.

Our hypothesis on the persistence of nutritional deficiencies in the midst of a high prevalence of so-called 'overnutrition' was confirmed in the present study. Anaemia and iron depletion were very highly prevalent, both reaching the level of a public health problem, mainly among women. The prevalence rate of vitamin A deficiency in our study was also above the threshold of public health significance of $15 \%{ }^{(32)}$. Moreover, evidence 
is increasingly supportive of an interaction between micronutrient deficiencies and $\mathrm{CMRF}^{(20,64,65)}$. The role of micronutrient malnutrition in non-communicable diseases is a compelling area for research, particularly in developing countries. Such research could contribute to knowledge on emerging cardiovascular risk factors, while providing further evidence for action.

Several limitations can be identified in our study. The cross-sectional design of the study does not allow any inference to be drawn with respect to the causal relationship between variables. Furthermore, the study is only representative of one district in Ouagadougou and the results cannot be extrapolated to the whole urban population of Burkina Faso without caution. Despite these limitations, the study provides useful data on both nutritional deficiencies and CMRF separately in the population as well as the prevalence of the double burden of malnutrition in connection with sociodemographic parameters.

The present study shows that the upward trend of nutrition-related chronic diseases is an overwhelming issue in adults of Ouagadougou. Worse still, it overlaps with micronutrient deficiencies, mainly among women, and among the uneducated and the poor. The prohibitive cost of curative treatment of nutrition-related chronic diseases, for both the patient and the health system mainly in developing countries, requires that increased attention be paid to preventive measures in adults but also throughout the life cycle. It is increasingly important for public health programmes to focus on healthy diets and lifestyle patterns (and their accessibility) that lead to optimal health outcomes at both ends of the spectrum. To develop such programmes, more research is required to indentify location-specific diets that may be protective against both nutritional deficiencies and CMRF. From now on, rather than focusing deficiencies or chronic diseases, it would be helpful to address both conditions in simultaneous strong public messages.

\section{Acknowledgements}

This work was supported by the Canadian International Development Agency. The authors declare that they have no competing interests. A.N.Z. developed the study protocol as his PhD project, he collected and analysed the data and wrote the manuscript. H.F.D. designed the study, supervised data analysis and thoroughly revised the manuscript. G.R. was involved in the study design and paper revision. B.S. conducted the local laboratory analyses and revised the manuscript. B.B. provided the sampling database, assisted with statistics and revised the manuscript. The authors gratefully acknowledge the Institut de Recherche en Sciences de la Santé (IRSS) and the Institut Supérieur des Sciences de la Population (ISSP) in Burkina Faso for technical and field support; and extend special thanks to Professor Somé Issa of the University of Ouagadougou and Professor JeanLouis Guéant of the University of Nancy for laboratory analyses. They also thank the study participants and the field workers.

\section{References}

1. Drewnowski A (2005) Concept of a nutritious food: toward a nutrient density score. Am J Clin Nutr 82, 721-732.

2. Drewnowski A \& Specter SE (2004) Poverty and obesity: the role of energy density and energy costs. Am J Clin Nutr 79, 6-16.

3. Popkin BM (2006) Global nutrition dynamics: the world is shifting rapidly toward a diet linked with noncommunicable diseases. Am J Clin Nutr 84, 289-298.

4. Despres JP, Cartier A, Cote M et al. (2008) The concept of cardiometabolic risk: bridging the fields of diabetology and cardiology. Ann Med 40, 514-523.

5. World Health Organization (2003) Diet, Nutrition and the Prevention of Chronic Diseases. Joint WHO/FAO Expert Consultation. WHO Technical Report Series no. 916. Geneva: WHO.

6. Abegunde DO, Mathers CD, Adam T et al. (2007) The burden and costs of chronic diseases in low-income and middle-income countries. Lancet 370, 1929-1938.

7. Misra A \& Khurana L (2008) Obesity and the metabolic syndrome in developing countries. J Clin Endocrinol Metab 93, 11 Suppl. 1, S9-S30.

8. Abubakari AR, Lauder W, Agyemang C et al. (2008) Prevalence and time trends in obesity among adult West African populations: a meta-analysis. Obes Rev 9, 297-311.

9. Agyemang C (2006) Rural and urban differences in blood pressure and hypertension in Ghana, West Africa. Public Health 120, 525-533.

10. Niakara A, Fournet F, Gary J et al. (2007) Hypertension, urbanization, social and spatial disparities: a cross-sectional population-based survey in a West African urban environment (Ouagadougou, Burkina Faso). Trans R Soc Trop Med Hyg 101, 1136-1142.

11. Abubakari AR, Lauder W, Jones MC et al. (2009) Prevalence and time trends in diabetes and physical inactivity among adult West African populations: the epidemic has arrived. Public Health 123, 602-614.

12. Black RE, Allen LH, Bhutta ZA et al. (2008) Maternal and child undernutrition: global and regional exposures and health consequences. Lancet 371, 243-260.

13. West KP Jr (2002) Extent of vitamin A deficiency among preschool children and women of reproductive age. J Nutr 132, 9 Suppl., 2857S-2866S.

14. Asfaw A (2007) Micronutrient deficiency and the prevalence of mothers' overweight/obesity in Egypt. Econ Hum Biol 5, 471-483.

15. Barquera S, Peterson KE, Must A et al. (2007) Coexistence of maternal central adiposity and child stunting in Mexico. Int J Obes (Lond) 31, 601-607.

16. Doak CM, Adair LS, Bentley M et al. (2005) The dual burden household and the nutrition transition paradox. Int J Obes (Lond) 29, 129-136.

17. Popkin BM (2002) The shift in stages of the nutrition transition in the developing world differs from past experiences! Public Health Nutr 5, 205-214.

18. Mendez MA, Monteiro CA \& Popkin BM (2005) Overweight exceeds underweight among women in most developing countries. Am J Clin Nutr 81, 714-721.

19. Monteiro CA, Conde WL \& Popkin BM (2004) The burden of disease from undernutrition and overnutrition in countries undergoing rapid nutrition transition: a view from Brazil. Am J Public Health 94, 433-434. 
20. Eckhardt CL, Torheim LE, Monterrubio E et al. (2008) The overlap of overweight and anaemia among women in three countries undergoing the nutrition transition. Eur J Clin Nutr 62, 238-246.

21. Vorster HH \& Kruger A (2007) Poverty, malnutrition, underdevelopment and cardiovascular disease: a South African perspective. Cardiovasc I Afr 18, 321-324.

22. van der Sande MA, Ceesay SM, Milligan PJ et al. (2001) Obesity and undernutrition and cardiovascular risk factors in rural and urban Gambian communities. Am J Public Health 91, 1641-1644.

23. City Development Strategy (2007) Etude diagnostique de l'agglomération de Ouagadougou. Ouagadougou: CDS.

24. Direction de la Nutrition (2006) Analyse complémentaire de la situation nutritionnelle au Burkina Faso: Rapport final. Ouagadougou: Ministère de la Santé du Burkina Faso.

25. Lohman T, Roche A \& Martorell R (1988) Anthropometric Standardization Reference Manual. Champaign, IL: Human Kinetics Books.

26. World Health Organization (2000) Obesity: Preventing and Managing the Global Epidemic. Report of a WHO Consultation on Obesity. WHO Technical Report Series no. 894. Geneva: WHO.

27. World Health Organization (1999) The Metabolic Syndrome. Definition, Diagnosis and Classification of Diabetes Mellitus and its Complications. Part 1: Diagnosis and Classification of Diabetes Mellitus. Geneva: WHO.

28. Chalmers J, MacMahon S, Mancia G et al. (1999) 1999 World Health Organization-International Society of Hypertension Guidelines for the management of hypertension. Guidelines sub-committee of the World Health Organization. Clin Exp Hypertens 21, 1009-1060.

29. World Health Organization \& International Diabetes Federation (2003) Screening for Type 2 Diabetes. WHO and IDF Meeting. Geneva: WHO.

30. International Task Force for Prevention of Coronary Heart Disease \& International Atherosclerosis Society (1998) Coronary disease: reducing the risk. The scientific background for primary and secondary prevention of coronary heart disease: a worldwide view. Nutr Metab Cardiovasc Dis 8, 205-227.

31. Matthews DR, Hosker JP, Rudenski AS et al. (1985) Homeostasis model assessment: insulin resistance and $\beta$-cell function from fasting plasma glucose and insulin concentrations in man. Diabetologia 28, 412-419.

32. World Health Organization (2009) Global Prevalence of Vitamin A Deficiency in Populations at Risk 1995-2005. WHO Global Database on Vitamin A Deficiency. Geneva: WHO.

33. World Health Organization (2004) Assessing the Iron Status of Populations: Including Literature Reviews. Report of a Joint WHO/CDC and Prevention Technical Consultation on the Assessment of Iron Status at the Population Level, 6-8 April 2004. Geneva: WHO.

34. Delisle HF (2008) Poverty: the double burden of malnutrition in mothers and the intergenerational impact. Ann NY Acad Sci 1136, 172-184.

35. Holdsworth M, Gartner A, Landais E et al. (2004) Perceptions of healthy and desirable body size in urban Senegalese women. Int J Obes Relat Metab Disord 28, 1561-1568.

36. Drewnowski A \& Darmon N (2005) Food choices and diet costs: an economic analysis. J Nutr 135, 900-904.

37. Murphy SP \& Allen LH (2003) Nutritional importance of animal source foods. J Nutr 133, 11 Suppl. 2, 3932S-3935S.

38. Amoah AG (2003) Hypertension in Ghana: a crosssectional community prevalence study in greater Accra. Ethn Dis 13, 310-315.

39. Edwards R, Unwin N, Mugusi F et al. (2000) Hypertension prevalence and care in an urban and rural area of Tanzania. J Hypertens 18, 145-152.
40. Whitworth JA (2003) 2003 World Health Organization (WHO)/International Society of Hypertension (ISH) statement on management of hypertension. J Hypertens $\mathbf{2 1}$, 1983-1992.

41. Ntandou G, Delisle H, Agueh V et al. (2009) Abdominal obesity explains the positive rural-urban gradient in the prevalence of the metabolic syndrome in Benin, West Africa. Nutr Res 29, 180-189.

42. Sodjinou R, Agueh V, Fayomi B et al. (2008) Obesity and cardio-metabolic risk factors in urban adults of Benin: relationship with socio-economic status, urbanisation, and lifestyle patterns. BMC Public Health 8, 84.

43. Mohan V, Nagalotimath SJ, Yajnik CS et al. (1998) Fibrocalculous pancreatic diabetes. Diabetes Metab Rev 14, 153-170.

44. Mohan V, Farooq S \& Deepa M (2008) Prevalence of fibrocalculous pancreatic diabetes in Chennai in South India. JOP 9, 489-492.

45. Alemu S, Dessie A, Seid E et al. (2009) Insulin-requiring diabetes in rural Ethiopia: should we reopen the case for malnutrition-related diabetes? Diabetologia 52, 1842-1845.

46. International Diabetes Federation (2009) Diabetes Atlas, 4th ed. Brussels: IDF.

47. Zoratti R (1998) A review on ethnic differences in plasma triglycerides and high-density-lipoprotein cholesterol: is the lipid pattern the key factor for the low coronary heart disease rate in people of African origin? Eur J Epidemiol 14, 9-21.

48. Sumner AE, Zhou J, Doumatey A et al. (2010) Low HDLcholesterol with normal triglyceride levels is the most common lipid pattern in West Africans and African Americans with metabolic syndrome: implications for cardiovascular disease prevention. CVD Prev Control 5 75-80.

49. Tishkoff SA, Reed FA, Friedlaender FR et al. (2009) The genetic structure and history of Africans and African Americans. Science 324, 1035-1044.

50. Delisle H \& Receveur O (2007) Malnutrition in developing countries. CMAJ 176, 65.

51. Monteiro CA, Moura EC, Conde WL et al. (2004) Socioeconomic status and obesity in adult populations of developing countries: a review. Bull World Health Organ 82, 940-946.

52. Ouedraogo HZ, Fournet F, Martin-Prevel Y et al. (2008) Socio-spatial disparities of obesity among adults in the urban setting of Ouagadougou, Burkina Faso. Public Health Nutr 11, 1280-1287.

53. Amoah AG (2003) Sociodemographic variations in obesity among Ghanaian adults. Public Health Nutr 6, 751-757.

54. Kamadjeu RM, Edwards R, Atanga JS et al. (2006) Anthropometry measures and prevalence of obesity in the urban adult population of Cameroon: an update from the Cameroon Burden of Diabetes Baseline Survey. BMC Public Health 6, 228.

55. Ntandou G, Delisle H, Agueh V et al. (2008) Physical activity and socioeconomic status explain rural-urban differences in obesity: a cross-sectional study in Benin (West Africa). Ecol Food Nutr 47, 313-337.

56. Montague CT \& O'Rahilly S (2000) The perils of portliness: causes and consequences of visceral adiposity. Diabetes 49, 883-888.

57. Lear SA, Humphries KH, Kohli S et al. (2007) The use of BMI and waist circumference as surrogates of body fat differs by ethnicity. Obesity (Silver Spring) 15, 2817-2824.

58. Camhi SM, Bray GA, Bouchard C et al. (2011) The relationship of waist circumference and BMI to visceral, subcutaneous, and total body fat: sex and race differences. Obesity (Silver Spring) 19, 402-408.

59. Katzmarzyk PT, Bray GA, Greenway FL et al. (2010) Racial differences in abdominal depot-specific adiposity 
in white and African American adults. Am J Clin Nutr 91, 7-15.

60. Deurenberg P, Yap M \& van Staveren WA (1998) Body mass index and percent body fat: a meta analysis among different ethnic groups. Int J Obes Relat Metab Disord 22, 1164-1171.

61. Rush EC, Freitas I \& Plank LD (2009) Body size, body composition and fat distribution: comparative analysis of European, Maori, Pacific Island and Asian Indian adults. Br J Nutr 102, 632-641.

62. Desilets MC, Garrel D, Couillard C et al. (2006) Ethnic differences in body composition and other markers of cardiovascular disease risk: study in matched Haitian and
White subjects from Quebec. Obesity (Silver Spring) 14, 1019-1027.

63. Carroll JF, Chiapa AL, Rodriquez M et al. (2008) Visceral fat, waist circumference, and BMI: impact of race/ethnicity. Obesity (Silver Spring) 16, 600-607.

64. Block G, Jensen CD, Norkus EP et al. (2008) Vitamin C in plasma is inversely related to blood pressure and change in blood pressure during the previous year in young Black and White women. Nutr J 7, 35.

65. Ford ES, Will JC, Bowman BA et al. (1999) Diabetes mellitus and serum carotenoids: findings from the Third National Health and Nutrition Examination Survey. Am J Epidemiol 149, 168-176. 